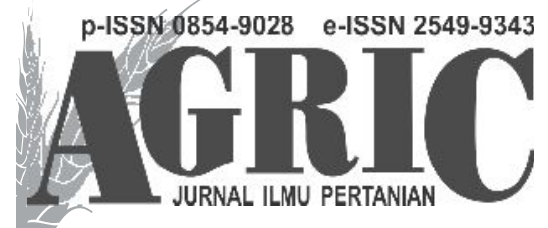

Fakultas Pertanian dan Bisnis Universitas Kristen Satya Wacana

Jl. Diponegoro 52-60 SALATIGA 50711 - Telp. 0298-321212 ext 354

email: jurnal.agric@adm.uksw.edu, website: ejournal.uksw.edu/agric

\title{
APLIKASI PUPUK SI ORGANIK DENGAN PUPUK N,P,K DALAM MENINGKATKAN P DAN SI TANAH PADA INCEPTISOL JATINANAGOR TERHADAP RESPON TANAMAN HANJELI (Coix lacryma Jobi L.)
}

APPLICATION OF ORGANIC FERTILIZER WITH N, P, K FERTILIZER IN INCREASING P AND SI SOIL IN JATINANAGOR INCEPTISOL TO HANJELI (Coix lacryma Jobi L.) PLANT RESPONSE

\author{
Eso Solihin ${ }^{1}$, Anni Yuniarti², Apong Sandrawati ${ }^{2}$, Zaenal Mutaqin ${ }^{2}$ \\ ${ }^{1}$ Universitas Padjadjaran, Jatinangor, 45363, \\ ${ }^{2}$ UniversitasPadjadjaran, Jatinangor, 45363 \\ Email korespondensi: esosolihin@yahoo.com
}

Diterima 8 Januari 2018, disetujui: 11 April 2018

\begin{abstract}
The objective of this research was to determine the effect of combinations of $N, P, K$ and organic silica fertilizers In Soil P and Si and growth of Job 's Tears (Coix Lacryma Jobi L.). This research began on May 2017 to October 2017. This research has been done in experimental of Faculty Agricultural, Padjadjaran University Jatinangor. The experiment was in Randomized Block Design (RCBD) consisting of ten treatments with three replications; (A) Control, (B) NPK standard, (C) NPK + 1/4 Silica Emulsion, (D) NPK + 1/2 Silica Emulsion, (E) NPK + 3/4 Silica Emulsion, $(F) N P K+1$ Emulsion of Ash Silica , (G) NPK +1/4 Nano Colloidal Silica, (H) NPK $+1 / 2$ Nano Colloidal Silica, (I) NPK + 3/4 Nano Colloidal Silica, (J) NPK + 1 Nano Colloidal Silica. The results showed that there was effect of Si fertilizer on soil P and plant growth. Treatment (J) NPK + 1 Colloidal Nano Silica gives Hanjeli the highest yield 5 MST, 7 MST, 9 MST and $11 \mathrm{MST}$ with plant height $3.58 \mathrm{~cm}, 10.58 \mathrm{~cm}, 17.17 \mathrm{~cm}$ and $18.00 \mathrm{~cm}$
\end{abstract}

Keywords: Soil phosphorus, soil Si, Hanjeli Growth, Silica Organic Fertilizer 


\begin{abstract}
ABSTRAK
Percobaan ini bertujuan untuk mengetahui pengaruh kombinasi N,P, K dan pupuk silika organik terhadap P, Si tanah dan pertumbuhan tanaman hanjeli (Coix lacryma-Jobi.L). Percobaan ini dilaksanakan pada bulan Mei 2017 sampai dengan Oktober 2017 di kebun percobaan Ciparanje Fakultas Pertanian Universitas Padjadjaran, Jatinangor, Sumedang. Metode yang digunakan adalah Rancangan Acak Kelompok (RAK) yang terdiri dari sepuluh perlakuan dengan tiga kali ulangan; (A) Kontrol, (B) NPK standar, (C) NPK + 1/4 Emulsi Abu Silika, (D) NPK + 1/2 Emulsi Abu Silika, (E) NPK + 3/4 Emulsi Abu Silika, (F) NPK + 1 Emulsi Abu Silika, (G) NPK + 1/4 Nano Koloid Silika, (H) NPK + 1/2 Nano Koloid Silika, (I) NPK + 3/4 Nano Koloid Silika, (J) NPK + 1 Nano Koloid Silika. Hasil penelitian menunjukkan bahwa terdapat pengaruh pemberian pupuk silika terhadap P, Si tanah dan pertumbuhan tanaman hanjeli. Perlakuan (J) NPK + 1 Nano Koloid Silika membeikan Hasil tertinggi tanaman 5 MST, 7 MST, 9 MST dan 11 MST dengan tinggi tanaman 3,58 cm, 10,58 cm, $17,17 \mathrm{~cm}$ dan $18,00 \mathrm{~cm}$.
\end{abstract}

Kata Kunci: Fosfor tanah, Si tanah, Pertumbuhan Hanjeli, Pupuk Silika Organik.

\section{PENDAHULUAN}

Indonesia merupakan negara agraris dengan iklim tropis dan didominasi oleh lahan suboptimal, salah satunya adalah Inceptisol. Sebaran tanah ini merupakan salah satu yang terluas diantara sekian banyak jumlah ordo tanah di Indonesia, sekitar 70,52 juta ha atau 37,5\% dari wilayah daratan Indonesia (Puslitanak, 2000). Mengingat sebaran Inceptisol sangat luas maka berpotensi untuk dikembangkan untuk lahan pertanian yang lebih produktif. Penyebaran tanah Inceptisol di Jawa Barat salah satunya terdapat di daerah Jatinangor.

Tanah Inceptisol asal Jatinangor memiliki kandungan C-organik rendah, $\mathrm{N}$-total rendah, P-tersedia sedang, KTK sedang dan $\mathrm{pH}$ tanah yang agak masam. Kekurangan unsur hara penting bagi tanaman, seperti $\mathrm{N}, \mathrm{P}, \mathrm{Ca}, \mathrm{Mg}$, dan Mo, serta tingginya kelarutan Al, Fe, dan Mn mencerminkan rendahnya kualitas tanah tersebut yang pada gilirannya akan menghambat penampilan dan produksi tanaman (Mokolobate dan Haynes, 2002). Oleh karena itu diperlukan upaya agar unsur hara yang dibutuhkan tanaman terpenuhi. Sehingga peranan pemupukan sangatlah penting untuk menyediakan unsur hara yang ada pada tanah Inceptisol. Menurut Mariam dan Hudaya (2002), menyatakan bahwa peningkatan hara pada inceptisol dapat dilakukan dengan pemberian pupuk anorganik dan organik. Salah satu solusi untuk menanggulanginya adalah pengunaan pupuk silika organik dan $\mathrm{N}, \mathrm{P}, \mathrm{K}$.

Salah satu sumber silika yang digunakan pada penelitian ini berasal dari hasil ekstaksi kulit biji hanjeli yang sudah dilakukan melewati proses penyosohan. Silika merupakan unsur hara terbanyak kedua yang berada di tanah dan silika dikenal sebagai unsur hara yang bermanfaat. Unsur silika dapat mendukung pertumbuhan yang sehat dan menghindari tanaman dari serangan penyakit, cekaman suhu, radiasi matahari dan defesiensi dan keracunan unsur hara lain (Balai Penelitian Tanah, 2010). Tanaman yang diberi silika akan membuat daun lebih tegak, tahan terhadap hama dan penyakit, dan mampu mengatasi kelebihan fosfor atau kekurangan fosfor. Pemberian silika juga mampu mengatasi keracunan Fe dan Mn pada tanaman (Sanchez, 1992). Pemberikan pupuk silika organik cair, di harapan dapat menyediakan unsur Si serta meningkatkan hasil tanaman hanjeli. 
Berdasarkan uraian di atas, diharapkan dengan diberikannya silika dari hasil ekstraksi kulit biji hanjeli sebagai pupuk silika bisa dijadikan alternatif yang perlu dipertimbangkan dalam usaha meningkatkan kandungan hara Inceptisol serta hasil tanaman hanjeli.

\section{METODE PENELITIAN}

Percobaan dilaksanakan di Kebun Percobaan Ciparanje Fakultas Pertanian Universitas Padjadjaran, Jatinangor, Sumedang. Lokasi penelitian memiliki ketinggian $\pm 800 \mathrm{~m}$ di atas permukaan laut, dengan ordo tanah yang digunakan adalah ordo Inceptisol Percobaan dilakukan mulai bulan Mei 2017 sampai dengan Oktober 2017. Percobaan menggunakan Rancangan Acak Kelompok (RAK), Sepuluh perlakuan dan tiga ulangan.

Perlakuan (A) Kontrol, (B) NPK standar, (C) NPK + 1/4 Emulsi Abu Silika, (D) NPK + 1/2 Emulsi Abu Silika, (E) NPK + 3/4 Emulsi Abu Silika, (F) NPK + 1 Emulsi Abu Silika, (G) NPK $+1 / 4$ Nano Koloid Silika, (H) NPK + 1/2 Nano Koloid Silika, (I) NPK +3/4 Nano Koloid
Silika, (J) NPK + 1 Nano Koloid Silika. Pada percobaan ini, menggunakan polibag dengan ukuran 40x40 $\mathrm{cm}$ dan terdapat dua unit percobaan yaitu: satu unit untuk pengamatan pada fase vegetatif maksimum dan satu unit lagi digunakan untuk pengamatan sampai fase generatif akhir. Metode pengukuran $P$ tanah menggunakan ekstrak $\mathrm{HCl} 25 \%$ dan untuk Si tanah dengan Gravimetri. Data hasil pengamatan dianalisis dengan sidik ragam pada tingkat kepercayaan 95\%. Untuk mengetahui perbedaan diantara perlakuan dengan Uji Jarak Ganda Duncan (DMRT) pada tingkat kepercayaan $95 \%$.

\section{HASIL DAN PEMBAHASAN}

\section{Kandungan Pdalam Tanah}

Data hasil pengamatan dan analisis ragam pengaruh penggunaan pupuk organik Si dengan $\mathrm{N}, \mathrm{P}, \mathrm{K}$ terhadap kandungan fosfor didalam tanah disajikan pada tabel 1. Hasil dari pengujian tersebut menunjukan perbedaan yang nyata antara perlakuan jika dibandingkan dengan kontrol.

Tabel 1 Pengaruh pemberian pupuk silika dan N,P,K terhadap P tanah

\begin{tabular}{|c|c|c|}
\hline Sandi & Perlakuan & $\begin{array}{l}\text { Kandungan P dalam Tanah } \\
(\mathrm{mg} / 100 \mathrm{~g})\end{array}$ \\
\hline A & Kontrol & $36,84 \mathrm{a}$ \\
\hline $\mathrm{B}$ & N, P, K Standar & $37,26 \mathrm{a}$ \\
\hline $\mathrm{C}$ & $\mathrm{N}, \mathrm{P}, \mathrm{K}+1 / 4$ Emulsi Abu Silika & $40,23 \mathrm{bc}$ \\
\hline $\mathrm{D}$ & $\mathrm{N}, \mathrm{P}, \mathrm{K}+1 / 2$ Emulsi Abu Silika & $40,53 \mathrm{bc}$ \\
\hline $\mathrm{E}$ & $\mathrm{N}, \mathrm{P}, \mathrm{K}+3 / 4$ Emulsi Abu Silika & 43,46 de \\
\hline $\mathrm{F}$ & $\mathrm{N}, \mathrm{P}, \mathrm{K}+1$ Emulsi Abu Silika & $43,70 \mathrm{de}$ \\
\hline G & N, P, K + 1/4 Koloid Nano Silika & $38,36 \mathrm{a}$ \\
\hline $\mathrm{H}$ & N, P, K + 1/2 Koloid Nano Silika & $41,38 \mathrm{~cd}$ \\
\hline $\mathrm{I}$ & N, P, K + 3/4 Koloid Nano Silika & $44,68 \mathrm{e}$ \\
\hline $\mathrm{J}$ & N, P, K +1 Koloid Nano Silika & $52,99 \mathrm{f}$ \\
\hline
\end{tabular}

Keterangan: Angka rerata yang diikuti huruf yang sama tidak berbeda nyata berdasarkan Uji Jarak Berganda Duncan pada Taraf $5 \%$. 
Pemberian pupuk silika dengan kombinasi N, $\mathrm{P}, \mathrm{K}$ dapat dilihat dari Tabel 1, yang menunjukkan perbedaan nyata antara satu perlakuan dengan perlakuan lainnya pada perlakuan A (Kontrol) menunjukan hasil kandungan $\mathrm{P}$ dalam tanah diakhir pengamatan sebesar $36,84 \mathrm{mg} /$ 100 g. Hal tersebut tidak jauh berbeda dengan perlakuan B (N, P, K Standar) dan perlakuan G (N, P, K + 1/4 Koloid Nano Silika) dengan kandungan $\mathrm{P}$ sebesar $37,26 \mathrm{mg} / 100 \mathrm{~g}$ dan $38,36 \mathrm{mg} / 100 \mathrm{~g}$. Sedangkan pada perlakuan $\mathrm{C}(\mathrm{N}, \mathrm{P}, \mathrm{K}+1 / 4$ Emulsi Abu Silika), D (N, P, $\mathrm{K}+1 / 2$ Emulsi Abu Silika), dan H (N, P, K + 1/2 Koloid Nano Silika) menunjukan hasil yang tidak berbeda nyata antar pelakuan dengan hasil 40,23 mg/ $100 \mathrm{~g}, 40,53 \mathrm{mg} / 100 \mathrm{~g}$ dan 41,38 $\mathrm{mg} / 100 \mathrm{~g}$.

Perlakuan E (N, P, K + 3/4 Emulsi Abu Silika), F (N, P, K + 1 Emulsi Abu Silika) dan I (N, P, $\mathrm{K}+3 / 4$ Koloid Nano Silika) memacu peningkatan P dalam tanah sebesar 43, $46 \mathrm{mg} / 100$ $\mathrm{g}, 43,70 \mathrm{mg} / 100 \mathrm{~g}$ dan 44,68 mg/ $100 \mathrm{~g}$. Sementara perlakuan J (N, P, K + 1 Koloid Nano Silika) menunjukan kandungan $P$ tertinggi yaiyu sebesar 52,99 mg/ 100 g. Peningkatan kandungan $\mathrm{P}$ dalam tanah akibat pemberian pupuk organik silikat diduga karena silika pada tanah berbentuk asam monsilikat, yang menghasilkan pengubahan $\mathrm{P}$ tidak larut menjadi $\mathrm{P}$ larut sehingga tersedia bagi tanaman. Silika berperan untuk menekan Fe dan Mn dalam tanaman, sehingga $P$ menjadi tersedai bagi tanaman. Hal ini sejalan dengan pernyataan Sudibyo (2008) pemberian Si pada tanahtanah di daerah ropika secara nyata dapat meningkatkan ketersediaan $\mathrm{P}$ dalam tanah.

\section{Kandungan Si dalam Tanah}

Berdasarkan hasil analisis varian kombinasi perlakuan pupuk organik Si dengan N,P,K dapat meningkatakan kandungan Si secara nyata. Hal tersebut disajikan pada Tabel 2.

Kandungan Si terendah terlihat pada perlakuan A (Kontrol) yaitu sebesar $21,06 \%$, sedangkan pada perlakuan B (N, P, K Standar) yaitu sebesar 21,96\%. Pada perlakuan dengan penambahan emulsi abu silika paling tinggi ditunjukan oleh perlakuan $\mathrm{F}(\mathrm{N}, \mathrm{P}, \mathrm{K}+1$ Emulsi Abu Silika) yaitu 24,80\% kemudian diikuti oleh perlakuan E, D, C yaitu 24,58\%, 24,14\% dan

Tabel 2 Pengaruh pemberian pupuk silika dan N,P,K terhadap Si tanah

\begin{tabular}{|c|c|c|}
\hline Sandi & Perlakuan & $\begin{array}{l}\text { Kandungan Si dalam } \\
\text { Tanah }(\%)\end{array}$ \\
\hline A & Kontrol & $21,06 \mathrm{a}$ \\
\hline B & N, P, K Standar & $21,96 \mathrm{~b}$ \\
\hline $\mathrm{C}$ & N, P, K + 1/4 Emulsi Abu Silika & $24,04 \mathrm{c}$ \\
\hline $\mathrm{D}$ & $\mathrm{N}, \mathrm{P}, \mathrm{K}+1 / 2$ Emulsi Abu Silika & $24,14 \mathrm{~cd}$ \\
\hline $\mathrm{E}$ & N, P, K + 3/4 Emulsi Abu Silika & $24,58 \mathrm{def}$ \\
\hline $\mathrm{F}$ & N, P, K + 1 Emulsi Abu Silika & 24,80 ef \\
\hline G & N, P, K + 1/4 Koloid Nano Silika & $23,87 \mathrm{c}$ \\
\hline $\mathrm{H}$ & N, P, K + 1/2 Koloid Nano Silika & 24,38 cde \\
\hline I & N, P, K + 3/4 Koloid Nano Silika & $24,95 \mathrm{f}$ \\
\hline $\mathrm{J}$ & N, P, K + 1 Koloid Nano Silika & $25,13 \mathrm{f}$ \\
\hline
\end{tabular}

Keterangan: Angka rerata yang diikuti huruf yang sama tidak berbeda nyata berdasarkan Uji Jarak Berganda Duncan pada Taraf $5 \%$. 
24,04\%. Perlakuan dengan penambahan nano koloid hasil tertinggi terlihat pada perlakuan J (N, P, K + 1 Koloid Nano Silika) yaitu 25,13\% diikuti oleh I, H dan G yaitu 24,95\%, 24,38\% dan $23,87 \%$. Pada perlakuan dengan penambahan pupuk Si terjadi perbedaan yang nyata antara perlakuan dengan pemberian emulsi dan nano silika. Menurut Amrullah (2015), umumnya tanah mengandung $5-40 \% \mathrm{Si}$, yaitu pada tanah liat satu kilogram mengandung Si sekitar 50-400 g. Si berfungsi menjaga kelembaban tanah, sehingga kandungan air dalam tanah terjaga. Hal ini sangat bermanfaat bagi tanaman agar tahan terhadap lingkungan yang sedikit airnya atau kering.

\section{Pertumbuhan Tanaman Hanjeli}

Data dan analisis statistik pengaruh jenis kompos terhadap tinggi tanaman disajikan pada Tabel 3. Hasil analisis ragam menunjukkan bahwa pemberian pupuk silika organik dan $\mathrm{N}, \mathrm{P}, \mathrm{K}$ tidak berpengaruh nyata terhadap tinggi tanaman pada 5 MST dan terdapat perbedaan yang nyata pada 7 MST, 9 MST dan 11 MST.
Hasil uji menggunakan uji jarak berganda Duncan pada taraf $5 \%$ seperti tercantum dalam Tabel 3.

Pertumbuhan tanaman pada 5 MST belum menunjukan perbedaan yang nyata, baru mulai terlihat nyata pada 7 MST sampai dengan 11 MST. Pada umur 5 MST tinggi tanaman paling tinggi ditunjukan oleh perlakuan $\mathrm{B}(\mathrm{N}, \mathrm{P}, \mathrm{K}$ Standar) yaitu $3,75 \mathrm{~cm}$.

Dari Tabel 3 dapat dilihat bahwa perlakuan J (N, P, K + 1 Koloid Nano Silika) merupakan perlakuan yang memberikan pengaruh yang nyata dibandingkan dengan kontrol dengan tinggi tanaman 10,58 cm, 17, $17 \mathrm{~cm}$ dan 18,00 cm pada 7 MST, 9 MST dan 11 MST. Hal ini diduga karena pengaruh dari pupuk Si yang berperan dalam memperbaiki ketegakan tanaman, sehingga terjadi peningkatan intersepsi cahaya matahari yang digunakan selama proses fotosintesis (Martanto, 2001). Dengan demikian, diduga perlakuan dosis pupuk silika dapat memicu pertumbuhan tinggi tanaman jika dibandingkan dengan perlakuan tanpa pupuk silika (kontrol).

Tabel 3 Hasil Tanaman Padi per Rumpun

\begin{tabular}{|c|c|c|c|c|c|}
\hline Sandi & Perlakuan & $5 \mathrm{MST}$ & $7 \mathrm{MST}$ & $9 \mathrm{MST}$ & $11 \mathrm{MST}$ \\
\hline A & Kontrol & $2,83 \mathrm{a}$ & $6,08 \mathrm{a}$ & $8,83 \mathrm{a}$ & $9,25 \mathrm{a}$ \\
\hline $\mathrm{B}$ & N, P, K Standar & $3,75 \mathrm{a}$ & $6,58 \mathrm{~b}$ & $9,83 \mathrm{~b}$ & $10,08 \mathrm{a}$ \\
\hline $\mathrm{C}$ & N, P, K + 1/4 Emulsi Abu Silika & $3,42 \mathrm{a}$ & $7,50 \mathrm{c}$ & $11,92 \mathrm{~d}$ & $12,25 \mathrm{bc}$ \\
\hline $\mathrm{D}$ & $\mathrm{N}, \mathrm{P}, \mathrm{K}+1 / 2$ Emulsi Abu Silika & $3,75 \mathrm{a}$ & $8,17 \mathrm{~d}$ & $12,58 \mathrm{e}$ & $12,92 \mathrm{~cd}$ \\
\hline $\mathrm{E}$ & $\mathrm{N}, \mathrm{P}, \mathrm{K}+3 / 4$ Emulsi Abu Silika & 3,83 a & 8,83 e & $13,75 \mathrm{~g}$ & $14,67 \mathrm{e}$ \\
\hline $\mathrm{F}$ & $\mathrm{N}, \mathrm{P}, \mathrm{K}+1$ Emulsi Abu Silika & $3,58 \mathrm{a}$ & $9,42 \mathrm{f}$ & $14,92 \mathrm{~h}$ & $15,75 \mathrm{f}$ \\
\hline $\mathrm{G}$ & N, P, K + 1/4 Koloid Nano Silika & 3,33 a & $7,25 \mathrm{c}$ & $10,75 \mathrm{c}$ & $11,42 \mathrm{~b}$ \\
\hline $\mathrm{H}$ & N, P, K + 1/2 Koloid Nano Silika & $3,42 \mathrm{a}$ & $8,42 \mathrm{~d}$ & $13,08 \mathrm{f}$ & $13,75 \mathrm{~d}$ \\
\hline I & N, P, K + 3/4 Koloid Nano Silika & $2,83 \mathrm{a}$ & $9,75 \mathrm{f}$ & $15,67 \mathrm{i}$ & $16,58 \mathrm{f}$ \\
\hline $\mathrm{J}$ & N, P, K +1 Koloid Nano Silika & $3,58 \mathrm{a}$ & $10,58 \mathrm{~g}$ & $17,17 \mathrm{j}$ & $18,00 \mathrm{~g}$ \\
\hline
\end{tabular}

Keterangan: Angka rerata yang diikuti huruf yang sama tidak berbeda nyata berdasarkan Uji Jarak Berganda Duncan pada Taraf 5\%. 


\section{KESIMPULAN}

Berdasarkan hasil penelitian, dapat ditarik kesimpulan sebagai berikut:

1. Terdapat perbedaan yang nyata antara pemberian pupuk silika organik dengan $\mathrm{N}, \mathrm{P}, \mathrm{K}$ terhadap keberadaan Posfor dan $\mathrm{Si}$ dalam tanah.

2. Perlakuan J (kombinasi pemberian N, P, K +1 Koloid Nano Silika) menunjukan hasil yang lebih tinggi dibandingkan dengan kontrol, pada pengukuran tinggi tanaman 5 MST, 7 MST, 9 MST dan 11 MST dengan tinggi tanaman $3,58 \mathrm{~cm}, 10,58 \mathrm{~cm}, 17,17$ $\mathrm{cm}$ dan $18,00 \mathrm{~cm}$.

\section{DAFTAR PUSTAKA}

Amrullah. 2015. Pengaruh Nano Silika terhadap Pertumbuhan, Respon Morfofisiologi dan Produktivitas Tanaman Padi (Oryza sativa L.). Tersedia di http:/ /repository.ipb.ac.id/handle/123456789/ 74526. (Diakses pada 28 September 2017).

Balai Penelitian Tanah. 2010. Mengenal Silika Sebagai Unsur Hara. Warta Penelitian dan Pengembangan Pangan. 32 (3): 1920.

Martanto EA. 2001. Pengaruh Abu Sekam Terhadap Pertumbuhan Tanaman dan Intensitas Penyakit Layu Fusarium Pada Tomat. Irian Jaya Agro. 8 (2):3740.
Mariam, S. dan R. Hudaya. 2002. Pengaruh Pupuk Organik dan SP-36 Terhadap Beberapa Sifat Kimia Andisol Serapan $P$ dan Hasil Tanaman Kubis (Brassica oleracea var. Grand 11). Jurusan Ilmu Tanah Fakultas Pertanian Universitas Padjadjaran. Bandung.

Mokolobate, M.S. and R.J. Haynes, 2002. Increases in $p H$ and Soluble Salts Influence the Effect that Additions of Organic Residues Have on Concentrations of Exchangeable and Soil Solution Aluminium. European J. Soil Sci., 53:481-489.

Pusat Penelitian Tanah dan Agroklimat. 2000. Atlas Sumberdaya Tanah Eksplorasi Indonesia, sekala 1:1.000.000. Pusat Penelitian Tanah dan Agroklimat. Badan Penelitian dan Pengembangan Pertanian. Departemen Pertanian. Bogor.

Sanchez, P.A. 1992. Sifat dan Pengolahan Tanah Tropika. Penerbit ITB Bandung. $397 \mathrm{hlm}$.

Sudibyo, B. S. B. 2008. Pengaruh Pemberian Si terhadap Serapan Si dan Hasil Jagung (Zea mays,. L) Pada Andisol. Skripsi Sarjana S1 Fakultas Pertanian UGM, Yogyakarta. 